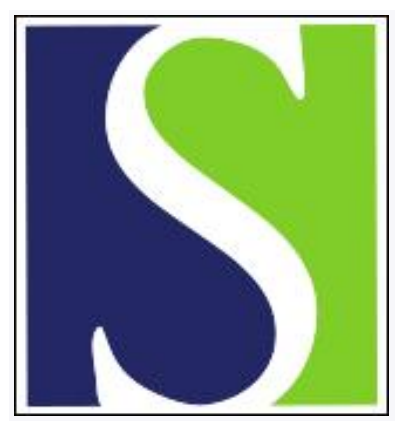

Scand J Work Environ Health 2002;28(3):205-207

https://doi.org/10.5271/sjweh.666

Issue date: Jun 2002

Inhalation of decomposed chlorodifluoromethane (freon-22) and myocardial infarction

by Sjögren B, Gunnare S, Sandler H

Affiliation: Work Environment Toxicology, Intistitute of Environmental Medicine, Karolinska Insititute, PO Box 210, SE-171 77

Stockholm, Sweden. Bengt.Sjogren@niwl.se

Refers to the following text of the Journal: 1999;25(1):39-41

Key terms: case study; chlorodifluoromethane; decomposed chlorodifluoromethane; decomposition; freon-22; HCFC-22; inflammation; myocardial infarction; R22

This article in PubMed: www.ncbi.nlm.nih.gov/pubmed/12109561

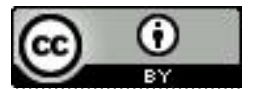




\title{
Inhalation of decomposed chlorodifluoromethane (freon-22) and myocardial infarction
}

\author{
by Bengt Sjögren, MD, ${ }^{1}$ Sara Gunnare, MSc, ${ }^{1,2}$ Håkan Sandler, MD ${ }^{3}$
}

\begin{abstract}
Sjögren B, Gunnare S, Sandler H. Inhalation of decomposed chlorodifluoromethane (freon-22) and myocardial infarction. Scand J Work Environ Health 2002;28(3):205-207.

After exposure to decomposed chlorodifluoromethane (freon-22), a 65-year-old man developed respiratory symptoms such as cough, blood-stained sputum, and increasing dyspnea. Three weeks later, his family doctor diagnosed infectious bronchitis. Another week later he died due to myocardial infarction. The discussion focuses on an inflammatory process caused by the inhalation of decomposed freon and its possible association with myocardial infarction.
\end{abstract}

Key terms decomposition, HCFC-22, inflammation, R22.

Freons such as chlorodifluoromethane (freon-22, R22 or HCFC-22) can be decomposed to phosgene and many other chlorinated or nonchlorinated hydrocarbons such as aldehydes and hydrochloric acid by electric arc welding (1). The two major responses to the inhalation of phosgene are inflammation and pulmonary edema (2). Aldehydes and hydrochloric acid are irritant chemicals. This is a case report of a man who was exposed to decomposed freon.

\section{Case description}

According to his son, the man, born in 1930, was in good health in general and had been awarded for donating blood 100 times. He was a never-smoker with no prior cardiac problems. He did not use any medication except when he sometimes had back pain. His perception of smell was severely deteriorated.

His main occupation for the last 30 years had been serving refrigerators and freezers. Repairing and exchanging broken compressors were part of this work.
The release of freon into the atmosphere could often not be avoided. Tubes and fittings were brazed with a hardsolder containing copper and silver, and the solders were melted by a flame of acetylene and oxygen. Released freon can be decomposed to phosgene and other chloro-containing compounds by the flame. Therefore it was likely that he had inhaled decomposed freon during his work, as he seldom used a respirator.

On the 25th of September 1995 he worked for about 8 hours replacing a tank containing freon-22. This work comprised at least two soldering operations. He inhaled decomposed products from freon and subsequently experienced respiratory symptoms that forced him to go out and breathe fresh air. During the following weeks he experienced respiratory symptoms (cough and bloodstained sputum) and increasing dyspnea and a decreasing physical capacity, but no chest pain. He consulted his family physician on 19 October 1995 . The symptoms and signs were interpreted as infectious bronchitis, and he was prescribed V-penicillin. According to his family doctor, he had been in generally good health previously.

1 Work Environment Toxicology, Institute of Environmental Medicine, Karolinska Institutet, Stockholm, Sweden.

2 Swedish National Institute for Working Life, Stockholm, Sweden.

3 Department Surgical Sciences/Forensic Medicine, Uppsala University, Uppsala, Sweden.

Reprint requests to: Dr Bengt Sjögren, Work Environment Toxicology, Institute of Environmental Medicine , Karolinska Institutet, Box 210, SE-171 77 Stockholm, Sweden. [E-mail: Bengt.Sjogren@niwl.se] 
He was admitted to the hospital on the 24th of October due to increasing dyspnea, but without any chest pain. Electrocardiography showed signs of myocardial infarction. Echocardiography showed decreased ventricular function and signs of a defect in the ventricular septum. The sedimentation rate was $29 \mathrm{~mm}$, and the leukocyte cell count was $17.9 \times 10^{9} / 1$. He died due to myocardial infarction on 27 October.

\section{Autopsy}

Autopsy revealed the following major findings. The heart was enlarged, weighing 620 grams with a right ventricle thickness of $8 \mathrm{~mm}$ and a left ventricle thickness of $18-20 \mathrm{~mm}$. There was some pericardial effusion and fibrinous depositions on the epicardium. In the right coronary vessel, about $20 \mathrm{~mm}$ from the coronary sinus, a plaque with an adherent thrombus was found that obliterated the lumen. The plaque was ruptured and subendothelial hemorrhage was observed. In other parts of the coronary arteries, patchy subendothelial lipid depositions, and some media thickening, but no calcifications, were found (grade 2/5). A well-demarcated, structureless, grey-brownish, $4 \times 3 \mathrm{~cm}$ area was found in the posteroseptal left-chamber area, $30 \mathrm{~mm}$ cranial from the apex. Microscopically this area was characterized by separated myofibrils, ongoing myocytolysis, and an accumulation of mainly mononuclear leukocytes between the myofibrils. Picro-Mallory staining indicated fibrin depositions on the subcapillary level. The myocardium did not contain any fibrous scars.

The lungs were distended and heavy (right $950 \mathrm{~g} \&$ left $840 \mathrm{~g}$ ). The mucosa of the main and stem bronchus was grossly irritated with pronounced hyperemia and thickening. The small airways were obliterated by opaque mucuslike secretions. Pronounced venular congestion and thickening of bronchial and pulmonary vessel walls were a constant finding. The respiratory epithelium was abundantly debridated, and peribronchial accumulation of lymphocytes and submucosal thickening with de novo vessels and glandular hyperplasia could be seen. Subpleural alveolar walls were frequently ruptured with formation of microemphysema. The interstitium was thickened in many places with atelectasis and fibrous proliferation, mimicking granuloma formation. Viral and microbiologic screening was negative. Taken altogether, the histological examination of the cardiorespiratory system pointed to a subacute inflammatory process rich in fibrin depositions and ending with a myocardial infarction without significant coronary sclerosis.

\section{Discussion}

It is known that habitual blood donors have a decreased risk for myocardial infarction (3), hypothetically due to depletion of body iron stores. Such a depletion could decrease the amount of injury-promoting iron in the myocardium, alter the activity of iron-dependent enzymes, increase plasma antioxidant capacity, and decrease lipid peroxidation in both the circulation and the vessel walls (3). Blood donors are also likely to be a selection of a more healthy part of the population.

A previous case report described a 43-year-old man who was involved in the demolition of a refrigeration plant. He was exposed to a peculiar "musty smelling gas" when cutting a pipe containing chlorodifluoromethane with a gas torch. He intitially experienced lacrimation, nausea, and cough with a burning sensation in his mouth and throat, and subsequently he experienced dyspnea and chest pain. He was admitted to a hospital for 24 hours for observation. His chest radiograph, electrocardiography, and arterial blood gases were normal. After his discharge he made a slow recovery, complaining of lethargy and exertional dyspnea, which prevented him from returning to work for 2 weeks (4). Our patient performed about the same operation, but he may have been exposed to higher concentrations of irritant chemicals since the period with respiratory symptoms, including dyspnea, was longer.

In 1984 Spodick and his co-workers reported an association between acute respiratory symptoms and the onset of myocardial infarction (5). More than 10 years later, Meier \& his co-workers found that, among persons without any history of clinical risk factors for myocardial infarction, acute respiratory tract infections were associated with an increased risk of myocardial infarction for a period of about 2 weeks (6). Chronic cough was studied in the original Framingham Heart Study. Chronic nonproductive cough (odds ratio 1.8, 95\% confidence interval 1.1-2.8) and productive cough (odds ratio 1.6, 95\% confidence interval 1.1-2.4) were both associated with the occurrence of myocardial infarction (7). In these calculations, adjustments were made for age, gender, smoking, forced vital capacity, diabetes mellitus, systolic blood pressure, left ventricular hypertrophy in electrocardiography, angina pectoris or coronary insufficiency, and total cholesterol level. These results thus confirmed the findings of Jousilahti and his co-workers some years earlier (8).

The man described in this case report could have been considered healthy, as he was a blood donor, a never-smoker, and had no significant coronary sclerosis. His productive cough and dyspnea increased after the exposure to decomposed freon. Chronic cough has previously been associated with increased concentrations of plasma fibrinogen (7). Hypothetically a raised 
level of several inflammation markers such as fibrinogen, a well-known risk indicator for myocardial infarction (9), may thus have played an important pathogenic role in the formation of the fatal myocardial infarction. This is an example of the general hypothesis linking urban and occupational air pollution to an inflammatory process associated with myocardial infarction $(10,11)$. Swine dust (12) and pollutants associated with tunnel construction (13) are two examples of air pollutants capable of raising plasma fibrinogen concentrations among volunteers and workers.

This case also illustrates the importance of using personal protective equipment when soldering or welding in an atmosphere containing freons. It also emphazises the need for early medical treatment in order to attenuate the inflammatory response.

\section{References}

1. Nieuwenhuizen MS, Groeneveld FR. Formation of phosgene during welding activities in an atmosphere containing chlorinated hydrocarbons. Am Ind Hyg Assoc J 2000;61:539-43.

2. Currie WD, Hatch GE, Frosolono MF. Pulmonary alterations in rats due to acute phosgene inhalation. Fundam Appl Toxicol 1987;8:107-14.

3. Tuomainen T-P, Salonen R, Nyyssönen K, Salonen JT. Cohort study of relation between donating blood and risk of myocardial infarction in 2682 men in eastern Finland. BMJ 1997;314:793-4.

4. Wyatt JP, Allister CA. Occupational phosgene poisoning: a case report and review. J Accid Emerg Med 1995;12:212-3.

5. Spodick DH, Flessas AP, Johnson MM. Association of acute respiratory symptoms with onset of acute myocardial infarction: prospective investigation of 150 consecutive patients and matched control patients. Am J Cardiol 1984;53:481-2.

6. Meier CR, Jick SS, Derby LE, Vasilakis C, Jick H. Acute respiratory-tract infections and risk of first-time acute myocardial infarction. Lancet 1998;351:1467-71.

7. Haider AW, Larson MG, O’Donnell CJ, Evans JC, Wilson PWF, Levy D. The association of chronic cough with the risk of myocardial infarction: the Framingham heart study. Am J Med 1999;106:279-84.

8. Jousilahti P, Vartiainen E, Tuomilehto J, Puska P. Symptoms of chronic bronchitis and the risk of coronary disease. Lancet 1996;348:567-72.

9. Danesh J, Collins R, Appleby P, Peto R. Association of fibrinogen, C-reactive protein, albumin, or leukocyte count with coronary heart disease. JAMA 1998;279:1477-82.

10. Seaton A, MacNee W, Donaldson K, Goddon D. Particulate air pollution and acute health effects. Lancet 1995;345:1768.

11. Sjögren B. Occupational exposure to dust: inflammation and ischaemic heart disease. Occup Environ Med 1997;54:4669.

12. Sjögren B, Wang Z, Larsson B-M, Larsson K, Larsson PH, Westerholm P. Increase in interleukin-6 and fibrinogen in peripheral blood after swine dust inhalation. Scand J Work Environ Health 1999;25:39-41.

13. Hilt B, Qvenild T, Holme J, Svendsen K, Ulvestad B. Increase in interleukin- 6 and fibrinogen after exposure to dust in tunnel construction workers. Occup Environ Med 2002;59:9-12.

Received for publication: 20 March 2002 